\title{
HLA-G Haplotypes Are Differentially Associated with Asthmatic Features
}

\author{
Camille Ribeyre ${ }^{1}$, Federico Carlini', Céline René2,3, François Jordier ${ }^{1,4}$, Christophe Picard ${ }^{1,4}$, \\ Jacques Chiaroni ${ }^{1,4}$, Laurent Abi-Rached ${ }^{5}$, Philippe Gouret ${ }^{6}$, Grégory Marin ${ }^{7,8}$, Nicolas \\ Molinari7,8, Pascal Chanez ${ }^{9,10}$, Julien Paganini, Delphine Gras ${ }^{10}$ and Julie Di Cristofaro ${ }^{1,4 *}$ \\ 'UMR7268 Anthropologie bio-culturelle, Droit, Ethique et Santé (ADES), "Biologie des Groupes Sanguins", Aix Marseille \\ Université, CNRS, Établissement Français du Sang (EFS), Marseille, France, ${ }^{2}$ Department of Immunology, CHRU de Montpellier, \\ University Hospital Saint-Eloi, Montpellier, France, ${ }^{3}$ Faculté de Médecine, University of Montpellier 1, Montpellier, France, \\ ${ }^{4}$ Établissement Français du Sang Alpes Méditerranée, Marseille, France, ${ }^{5}$ Equipe ATIP, URMITE UM63 CNRS 7278 IRD 198 \\ INSERM 1095, IHU Méditerranée Infection, Aix Marseille Université, Marseille, France, ${ }^{6}$ Xegen, Gemenos, France, ${ }^{7}$ Institut \\ Montpelliérain Alexander Grothendieck, CNRS, University of Montpellier, Montpellier, France, ${ }^{8}$ Department of Statistics, \\ University of Montpellier Hospitals, Montpellier, France, ${ }^{9}$ Clinique des Bronches, Allergie et Sommeil, AP-HM Hôpital Nord, \\ Marseille, France, ${ }^{10}$ INSERM U1067, CNRS UMR 7333, Aix Marseille Université, Marseille, France
}

\section{OPEN ACCESS}

Edited by: Uday Kishore, Brunel University London, United Kingdom

Reviewed by: Maura Rossetti, University of California, Los Angeles, United States Silke Paust, Baylor College of Medicine, United States

Sumati Rajagopalan, National Institute of Allergy and Infectious Diseases (NIH), United States

*Correspondence: Julie Di Cristofaro julie.dicristofaro@efs.sante.fr

Specialty section:

This article was submitted to Molecular Innate Immunity, a section of the journal

Frontiers in Immunology

Received: 13 November 2017 Accepted: 31 January 2018 Published: 23 February 2018

Citation:

Ribeyre C, Carlini F, René C, Jordier F, Picard C, Chiaroni J, Abi-Rached L, Gouret P, Marin G, Molinari N, Chanez P, Paganini J,

Gras D and Di Cristofaro J (2018) HLA-G Haplotypes Are Differentially Associated with Asthmatic Features.

Front. Immunol. 9:278 doi: 10.3389/fimmu.2018.00278
Human leukocyte antigen (HLA)-G, a HLA class lb molecule, interacts with receptors on lymphocytes such as T cells, B cells, and natural killer cells to influence immune responses. Unlike classical HLA molecules, HLA-G expression is not found on all somatic cells, but restricted to tissue sites, including human bronchial epithelium cells (HBEC). Individual variation in HLA-G expression is linked to its genetic polymorphism and has been associated with many pathological situations such as asthma, which is characterized by epithelium abnormalities and inflammatory cell activation. Studies reported both higher and equivalent soluble HLA-G (sHLA-G) expression in different cohorts of asthmatic patients. In particular, we recently described impaired local expression of HLA-G and abnormal profiles for alternatively spliced isoforms in HBEC from asthmatic patients. sHLA-G dosage is challenging because of its many levels of polymorphism (dimerization, association with $\beta 2$-microglobulin, and alternative splicing), thus many clinical studies focused on HLA-G single-nucleotide polymorphisms as predictive biomarkers, but few analyzed HLA-G haplotypes. Here, we aimed to characterize HLA-G haplotypes and describe their association with asthmatic clinical features and SHLA-G peripheral expression and to describe variations in transcription factor (TF) binding sites and alternative splicing sites. HLA-G haplotypes were differentially distributed in 330 healthy and 580 asthmatic individuals. Furthermore, HLA-G haplotypes were associated with asthmatic clinical features showed. However, we did not confirm an association between sHLA-G and genetic, biological, or clinical parameters. HLA-G haplotypes were phylogenetically split into distinct groups, with each group displaying particular variations in TF binding or RNA splicing sites that could reflect differential HLA-G qualitative or quantitative expression, with tissue-dependent specificities. Our results, based on a multicenter cohort, thus support the pertinence of HLA-G haplotypes as predictive genetic markers for asthma.

Keywords: human leukocyte antigen-G, regulatory regions, haplotypes, asthma, phylogeny, alternative splicing, transcription factor binding site

Abbreviations: HLA, human leukocyte antigen; CTL, cytotoxic T-lymphocyte; NK, natural killer; SNP, single-nucleotide polymorphism; sHLA-G, soluble HLA-G; UTR, untranslated region; URR, upstream regulatory region; HBEC, human bronchial epithelium cells; VBMD, volunteer bone marrow donors; BMI, body mass index; NGS, next-generation sequencing; ACT, asthma control test; ICU, intensive care unit. 


\section{INTRODUCTION}

Human leukocyte antigen-G (HLA-G), a member of the HLA class Ib (non-classical) family, modulates natural killer (NK) cells and cytotoxic T-lymphocyte-mediated activity as well as B-lymphocyte proliferation. HLA-G is also involved in epithelial cell differentiation (1-3).

Human leukocyte antigen- $G$ is expressed by a restricted pattern of cells including human bronchial epithelium cells (HBEC) and displays interindividual variation expression in physiological conditions. The mechanisms responsible for tissue-specific expression and interindividual HLA-G expression variation are of utmost importance since HLA-G expression is associated with many diseases involving immune system surveillance and inflammatory disease, such as asthma $(3,4)$.

Asthma is characterized by structural changes in the airways with abnormalities of the epithelium and concomitant recruitment, survival, and activation of inflammatory cells. In asthma, soluble HLA-G (sHLA-G) expression was reported to be higher in bronchoalveolar lavage (BAL) from asthmatic individuals and in both plasma and serum from atopic asthmatic children, whereas others reported no difference in non-allergic asthmatics (5-8). In BAL from asthmatic patients, however, sHLA-G expression was reported to be inversely correlated with markers of asthma inflammation (9). Our group reported an impairment of full-length protein HLA-G expression in HBEC from asthmatic patients and abnormal expression of alternatively spliced membrane-bound (HLA-G1 to 4) and soluble (HLA-G5 to 7) forms (10). Both HLA-G1 and -G5 isoforms reduced NK cell cytotoxicity with an additive effect, and HLA-G2,-G4, and -G6 were described as functional, whereas conflicting results were published concerning HLAG3 (11-14).

Human leukocyte antigen-G tissue-specific expression is reported to be driven by a $12 \mathrm{~kb}$ upstream enhancer site, defined as cis-regulatory Enhancer L (15). Concerning interindividual variation expression, $H L A-G^{\star} 01: 04$ has been associated with high HLA-G secretion and $G^{\star} 01: 03$ and $G^{\star} 01: 05 N$ with low HLA-G secretion (3). In the $3^{\prime}$ untranslated region (UTR), conflicting results were reported concerning association of HLA-G expression and the ex8 ins/del polymorphism (16); the $3142 \mathrm{G}$ allele was identified as a binding site for the microRNA-152 family (17) and $3187 \mathrm{~A} / \mathrm{G}$ and $3196 \mathrm{C} / \mathrm{G}$ were reported to influence mRNA stability. $3^{\prime}$ UTR haplotypes differentially influenced HLA-G expression in gene reporter assays conducted in vitro (18). However, in silico analysis of 3'UTR haplotypes suggested that most microRNAs targeting $H L A-G$ in a strong or specific manner are not influenced by $3^{\prime}$ UTR single-nucleotide polymorphisms (SNPs) and that $3^{\prime}$ UTR haplotypes display equivalent means of microRNA binding (19). Polymorphism in the $5^{\prime}$ upstream regulatory region (URR) within regulatory elements, such as $-1305 \mathrm{G}>\mathrm{A},-964 \mathrm{G}>\mathrm{A} \quad 725 \mathrm{C}>\mathrm{G}>\mathrm{T}$, $-716 \mathrm{G}>\mathrm{T}$ and $-56 \mathrm{C}>\mathrm{T}$, were reported to impact HLA-G expres$\operatorname{sion}(3,20)$.

Human leukocyte antigen-G protein dosage has its drawbacks, and therefore, many teams have studied the association between HLA-G SNP and pathological situations (3). Few studies have focused on $H L A-G$ genetic haplotypes as predictive biomarkers
(21). HLA-G haplotypes are defined as SNPs being in Linkage Disequilibrium; Castelli et al. first described a restricted number of HLA-G haplotypes using SNPs in the $5^{\prime} \mathrm{URR}, 3^{\prime} \mathrm{UTR}$, and coding regions in a Brazilian population (22). This low variability suggests a stabilizing selective effect on $H L A-G$ haplotypes which could reflect a synergic effect of HLA-G SNPs. We previously characterized a deleterious association of two HLA-G haplotypes, $H L A-G^{*} 01: 04-U T R 3$ and $H L A-G^{*} 01: 06-U T R 2$, in lung transplantation outcome and in lung inflammatory diseases such as cystic fibrosis (23). Although the HLA-G gene was identified as an asthma susceptibility gene and SNPs -964 and 3142 were associated with asthma $(17,24-27)$, no study so far has described the haplotypes effect, shown to be more relevant than SNPs to predict sHLA-G dosage $(28,29)$, in asthma clinical studies.

We aimed to investigate the association of $H L A-G$ haplotypes and sHLA-G peripheral expression with clinical features of asthma. We then aimed to analyze phylogenetic relationships, variations at potential transcription factor (TF) binding sites and alternative splicing sites between HLA-G haplotypes that could account for their differential association with asthmatic features.

\section{MATERIALS AND METHODS}

\section{Samples}

This study was carried out in accordance with the French Public Health Code (art L1221-1). All subjects gave written informed consent in accordance with the Declaration of Helsinki. Three hundred and thirty volunteer bone marrow donors from France were recruited, blood donations were collected, and DNA was extracted from a $200 \mu$ lotal blood sample using the QIAmp Blood DNA Mini kit (Qiagen, France) in accordance with BSL-2 practices. A medical interview was carried out prior to blood donation to exclude donors with medical contraindications such as severe asthma, respiratory failure, or allergies. Five hundred and ninety asthmatic patients enrolled in a French asthmatic multicenter cohort (Cohorte Obstruction Bronchique et Asthme, INSERM Hôpital Bichat, CNIL 28/01/2008) were included in the study. DNA samples with known genotype were used as control. Biological samples included 590 samples of DNA, 582 of serum, and a further 528 of serum collected 1 year after the first sample. Patient data were categorized into biological and clinical data and asthma severity according to the Guidelines for the Diagnosis and Management of Asthma, NHLBI 2007. Healthy individuals (HI) and asthmatic patient characteristics are detailed in Table 1.

\section{HLA-G Next Generation Sequencing}

The HLA-G gene was sequenced from position -1983 to +3447 by next-generation sequencing (NGS). A 5,430 pb long amplicon was generated by PCR; primer sequences were 5'AGGAGCTGACA CAGGAGGAA3' and 5'CAGCTGAGCAGTGACCACAT3'; and amplification was performed using the Long Range PCR Kit (Qiagen, France). PCR fragments were sequenced using an NGS platform (MiSeq, Illumina, The Netherlands). 
TABLE 1 | Healthy individuals $(\mathrm{HI})$ and asthmatic patients' [Cohorte Obstruction Bronchique et Asthme (COBRA)] characteristics (NA, non-applicable).

\begin{tabular}{|c|c|c|}
\hline Patient data & HI & COBRA \\
\hline Number of patients & 330 & 590 \\
\hline Age (years) (median and range) & $41(18-59)$ & $33(16-83)$ \\
\hline Sex (ratio) & 1.60 & 1.75 \\
\hline Associated pathologies, $\geq 1$ (\%) & 0 & 49 \\
\hline $\begin{array}{l}\text { Hospitalization for asthma within the last } \\
12 \text { months, }=0,=1, \geq 2(\%)\end{array}$ & 0 & $78,15,7$ \\
\hline Reanimation history for asthma (\%) & 0 & 21 \\
\hline $\begin{array}{l}\text { Emergency consultation for asthma within the } \\
\text { last } 12 \text { months, } \geq 1(\%)\end{array}$ & 0 & 45 \\
\hline Exacerbations within the last 12 months, $\geq 1(\%)$ & 0 & 65 \\
\hline Blood eosinophils/mm³ (median and range) & NA & $321(0-3,321)$ \\
\hline FEV2 (median and range) & NA & $79(18-463)$ \\
\hline Allergy (\%) & 0 & 68 \\
\hline $\begin{array}{l}\text { Control of asthma, controlled, partly controlled, } \\
\text { and uncontrolled }(\%)\end{array}$ & NA & $26,31,43$ \\
\hline Asthma control test score (median and range) & NA & $14(4-25)$ \\
\hline
\end{tabular}

\section{HLA-G Allele and UTR Typing and Full-Length Sequence Regulatory Region Analysis}

HLA-G NGS data were analyzed through PolyPheMe, specific software developed by the Xegen Company (France). HLA-G allelic assignment at eight digits was based on the HLA sequences listed in the official IMGT/HLA database (30). Regulatory regions were typed at low and high resolutions. Both low and high resolutions of regulatory region haplotypes were defined using PHASE and an EM algorithm implemented in the Gene[Rate] computer tools (31). Low-resolution typing (UTR 1-8) was performed as previously described (29) according to eight SNPs (-725/ rs1233334, -716/rs2249863, -201/rs1233333, -56/rs17875397, ins/ del exon 8/rs66554220, 3142/rs1063320, 3187/rs9380142, and $3196 /$ rs1610696). High-resolution typing of regulatory regions (H1 to H74) was performed according to all polymorphic variations from position -1983 to -1 in $5^{\prime}$ URR and from +2540 to +3447 in 3'UTR. HLA-G haplotype identification numbers were coded as previously described (21). Allelic, UTR, and haplotype frequencies were estimated using PHASE and an EM algorithm implemented in the Gene[Rate] computer tools (31).

\section{Serum sHLA-G Protein Measurement}

Soluble HLA-G (sHLA-G), i.e., peripheral HLA-G expression, was quantified in sera from 582 asthmatic patients and 528 sera collected 1 year after the first sample. All serum samples were stored at $-80^{\circ} \mathrm{C}$ prior to analysis. Measurement of soluble isoforms sHLA-G1 and sHLA-G5 was performed in duplicate on serum samples using the ELISA test (Biovendor ${ }^{\circledast}$, Czech Republic; capture antibody: MEM-G/9) according to the manufacturer's protocol.

\section{Association of HLA-G Alleles and Haplotypes with Asthmatic Features and Peripheral sHLA-G Dosage}

Missing data led to the exclusion of the concerned sample from further analyses. No multiple imputation was used. Genetic data frequencies between $\mathrm{HI}$ and asthmatic patients were compared with Chi-square tests.

Associations between patients' asthmatic features, sHLA-G expression, and genetic polymorphism were tested with logistic regressions when the predicted variable was categorical and general linear regression when the predicted variable was quantitative. Univariate analyses were performed on each of these asthmatic features: eosinophil count $\left(/ \mathrm{mm}^{3}\right)$, history of near-fatal asthma, asthma control, asthma control test score, asthmatic exacerbations within the last 12 months, emergency consultation for asthma within the last 12 months, hospitalization within the last 12 months because of asthma, intensive care unit stays, according to biological parameters [gender, body mass index (BMI), occupational exposure, tobacco use, allergies, maternal asthma, and paternal asthma], HLA-G predictors (HLA-G alleles, $H L A-G$ regulatory regions typed at low resolution, and $H L A-G$ regulatory regions typed at high resolution), and sHLA$G$ serology and differences between sHLA-G dosage results in sera collected at a 1-year interval. Univariate analyses were also performed on sHLA-G dosage and differences between sHLA-G dosage results in sera collected at a 1-year interval according to clinical and biological parameters such as gender, height, weight, BMI, occupational exposure, tobacco use, allergies, associated pathologies, maternal asthma, paternal asthma, treatment for asthma or for allergy (CO intake, anticholinergics, anti-IgE, anti-leukotrienes, theophylline, antihistamines, anti-RGO, antihypertensives, statins, and fibrates), month of serum collection, and genetic parameters (HLA-G alleles, HLA-G UTR, and HLA-G haplotypes). The False Discovery Rate correction for multiplicity was applied; however, no power analysis was performed. Variables with $p$ values below 0.05 and corrected $p$ values below 0.20 in univariate analysis were further investigated in multivariate analysis. Association results with quantitative variables are expressed as estimates and standard errors (Std error), whereas association results with qualitative variables are expressed as odd ratios (OR) and $95 \%$ confidence intervals.

\section{HLA-G Full-Length Sequence Phylogenetic Analysis}

$H L A$-G full-length sequences from position -1983 to +3447 were aligned using the multiple sequence alignment tool MUSCLE in the Molecular Evolutionary Genetics Analysis (MEGA) software version 7.0 (32). Evolutionary analyses were conducted in MEGA7. Evolutionary relationships among $H L A-G$ full-length sequences were inferred using the neighbor-joining (NJ) method with 1,000 replicates. Evolutionary distances were computed using the $p$-distance method, and units were the number of base differences per site. Analysis involved gorilla $H L A-G$ genomic sequence as an outgroup (accession number CU104658.1).

\section{TF Binding Site Analysis and TF Expression in the Lungs and in Blood}

Each SNP in the 5'UTR was analyzed for potential TF binding site variation with the AliBaba 2.1 and ConSite programs. TFs found to have differential binding sites between $H L A-G$ haplotypes were checked for their tissue-specific expression (blood and lungs) 
in NCBI and Tissue-specific Gene Expression and Regulation (TiGER) databases (33). NCBI data included the "HPA RNA-seq normal tissues" project, i.e., RNA-seq performed on 27 different tissue samples from 95 human individuals and the "Illumina bodyMap2 transcriptome" project, i.e., transcription profiling by high-throughput sequencing of RNA from 16 different human tissues.

\section{Splicing Site Variation Analysis}

Variation in splicing sites was studied for alleles sharing identical or similar UTR haplotypes using the Human Splicing Finder program (34). This program combines different algorithms to identify and predict the effect of mutations on acceptor and donor splice site motifs.

\section{RESULTS}

\section{HLA-G Haplotypes Are Differentially Distributed in Healthy and Asthmatic Individuals and Correlate with Asthmatic Features}

Next generation sequencing typing was successful in 317 (96\%) $\mathrm{HI}$ and 582 (98\%) asthmatic patients. Thirty-seven SNPs, 1 base deletion, 1 base insertion, and a $14 \mathrm{bp}$ insertion were validated through Xegen pipeline analysis in the regulatory regions 5'URR and $3^{\prime}$ UTR from position -1983 to +3447 ; all were previously described $(30,35,36)$. HLA-G sequencing data have been submitted to the NCBI public data base (Table 2).

$H L A-G$ alleles were typed at maximum resolution (eight digits) and regulatory regions (UTR1-8) were typed at low resolution according to eight SNPs in 5'URR and at high resolution based on all 28 polymorphisms in the $5^{\prime}$ URR and 12 polymorphisms in the $3^{\prime}$ UTR. Fifteen haplotypes with frequency above $0.3 \%$ displayed $94 \%$ of the cumulated frequencies. Their description and frequencies are detailed in Table 2.

Whereas high-resolution typing of regulatory region haplotypes did not discriminate between low-resolution typed haplotypes (such as UTR2/H10, UTR3/H23, and UTR7/H16), some UTRs were refined (such as UTR1, UTR4, UTR5, and UTR6, respectively, split into three, two, two, and four haplotypes). Several eight-digit alleles were associated with one haplotype, except for $G^{\star}$ 01:01:01:01 and $G^{\star}$ 01:03:01:02, which were associated with several haplotypes, and $G^{\star}$ 01:01:03:03 and UTR7/H16 that were exclusively associated together.

H23-UTR3-G*01:04:01 and H23-UTR3-G*01:04:04 were, respectively, higher and lower in $\mathrm{HI}$ than in asthmatic patients ( $p=0.044$ and $p=0.012$ ); H04-UTR4- $G^{\star} 01: 01: 01: 05$ and H02UTR4- $G^{\star} 01: 01: 01: 05$ were both higher in HI than in asthmatic patients $(p=0.015$ and $p=0.009)$, finallyH47-UTR6- $G^{\star} 01: 01: 01: 04$ was not observed in HI ( $p=0.002$ ) (Table 2).

Correlations between HLA-G alleles, UTR, or haplotypes and asthmatic patient data investigated in multivariate analysis are shown in Tables 3A,B. Variables included in the multivariate

TABLE 2 | HLA-G regulatory region haplotypes identifying number (ID), nucleotide variations, untranslated region (UTR) and allelic association, and frequencies estimated by EM algorithm in healthy individuals $(\mathrm{HI})$ and asthmatic patients [Cohorte Obstruction Bronchique et Asthme (COBRA)] with a total frequency higher than $0.3 \%$ estimated by the EM algorithm: ID, nucleotide variations, UTR and allelic association, and frequencies in HI and asthmatic patients (COBRA).

Haplotype Nucleotides variations, UTR and allele association ID

$\begin{array}{lccc}\begin{array}{l}\text { GenBank } \\ \text { accession } \\ \text { number }\end{array} & \text { HI (\%) } & \begin{array}{c}\text { COBRA } \\ (\%)\end{array} & p \text {-value } \\ & & & \end{array}$

\begin{tabular}{|c|c|c|c|c|c|}
\hline H05 & T C T G A G A A C G C C T A G A G * A C A G C G G C G C G G C D T G C C C G C G UTR1 G*01:01:01:01 & MG825353 & $11(1.73)$ & $33(2.83)$ & 0.149 \\
\hline H54 & T С T G A GA A C G C C T A G A G G A C A A C G G C G C G G C D T G C C C G C G UTR1 G*01:01:01:01 & MG825355 & $2(0.31)$ & $5(0.42)$ & 0.71 \\
\hline $\mathrm{H} 10$ & C A C A G G T A C A T C G G T A A * A C C A G G G A A C A T G I T C C C G A G G UTR2 G*01:01:02:01 & MG825359 & $125(19.7)$ & $232(19.9)$ & 0.912 \\
\hline $\mathrm{H} 10$ & C A C A G G T A C A T C G G T A A * A C C A G G G A A C A T G I T C C C G A G G UTR2 G*01:01:02:02 & MG825362 & $3(0.47)$ & $8(0.68)$ & 0.578 \\
\hline $\mathrm{H} 23$ & T C C A G A A A C A T C G G T A A * A C C A G G G A A C G T G D T C C C G A C G UTR3 G*01:04:01 & MG825349 & $41(6.46)$ & $50(4.29)$ & 0.044 \\
\hline $\mathrm{H} 23$ & T C C A G A A A C A T C G G T A A * A C C A G G G A A C G T G D T C C C G A C G UTR3 G01:04:04 & MG825348 & $9(1.41)$ & $40(3.43)$ & 0.012 \\
\hline $\mathrm{HO4}$ & T C T G A G A A T G C G T A G A G * A C A A C G G C G C G G C D C G C C C A C G UTR4 G*01:01:01:05 & MG825356 & $51(8.04)$ & $60(5.15)$ & 0.015 \\
\hline $\mathrm{HO2}$ & T C T G A G A A C G C G T A G A G * A C A A C G G C G C G G C D C G C C C A C G UTR4 G*01:01:01:05 & MG825358 & $44(6.94)$ & $48(4.12)$ & 0.009 \\
\hline $\mathrm{H} 21$ & T C C G G G A G C G C T T A G G G * A G A A G A A A G T G T G I T C C T G A C G UTR5 G*01:03:01:02 & MG825350 & $10(1.57)$ & $31(2.66)$ & 0.14 \\
\hline $\mathrm{H} 49$ & T C T G A G A A C G C C T A G A G * A C A A C G G C G C G G C D C G C C C A C G UTR6 G*01:01:01:06 & MG825365 & $1(0.15)$ & $10(0.85)$ & 0.068 \\
\hline $\mathrm{H} 16$ & C A C A G G T A C A T C G G T A A * A C C A G G G A A C G T G I T C A T G A C G UTR7 G*01:01:03:03 & MG825347 & $30(4.73)$ & $73(6.27)$ & 0.179 \\
\hline
\end{tabular}

Significant p-values (chi-square test) are in bold. 
TABLE 3 | (A,B) Genetic variables with p-value < 0.05 in multivariate analysis associated with Cohorte Obstruction Bronchique et Asthme asthmatic patient data (OR, odds ratio; $95 \% \mathrm{Cl}$, confidence interval 95\%; and Std error, standard error).

(A)

\begin{tabular}{|c|c|c|c|c|c|}
\hline \multirow{3}{*}{$\begin{array}{l}\text { Asthmatic patient data } \\
\text { Asthmatic exacerbation within the last } 12 \text { months } \\
\text { History of near-fatal asthma }\end{array}$} & \multirow{2}{*}{$\begin{array}{l}\text { Variable } \\
\text { UTR2 } 1 \text { vs. } 0\end{array}$} & \multirow{2}{*}{$\begin{array}{c}\text { OR } \\
1.62\end{array}$} & \multicolumn{2}{|c|}{$95 \% \mathrm{Cl}$} & \multirow{2}{*}{$\frac{\boldsymbol{p} \text {-Value }}{0.011}$} \\
\hline & & & 1.115 & 2.355 & \\
\hline & UTR7 1 vs. 0 & 1.838 & 1.019 & 3.313 & 0.043 \\
\hline \multicolumn{6}{|l|}{ (B) } \\
\hline Asthmatic patient data & Variable & Estimate & Std error & & $p$-Value \\
\hline Eosinophil count $\left(/ \mathrm{mm}^{3}\right)$ & UTR2 1 & 73.275 & 28.75 & & 0.011 \\
\hline
\end{tabular}

Analyses were performed with logistic regressions when the predicted variable was categorical and general linear regression when the predicted variable was quantitative.

models were gender and UTR2 for asthmatic exacerbation; gender, age, tobacco use, and UTR7 for acute asthma recurrence; and BMI, age, maternal asthma, tobacco use, UTR2, and UTR3 for eosinophil count. UTR2 $(N=369)$ was associated with asthmatic exacerbation within the last 12 months $[p=0.011$; OR $=1.62$ (1.115-2.355)] and eosinophil count $\left(/ \mathrm{mm}^{3}\right) \quad(p=0.011$; estimate $=73.275$, Std error $=28.75)$. UTR7 $(N=76)$ was associated with acute asthma recurrence $[p=0.043$; OR $=1.838$ (1.019-3.313)].

\section{Peripheral sHLA-G Expression Is Not Associated with Genetics or Asthmatic Features}

Serum sHLA-G measurements from asthmatic patients were 17.1 (0-493) UI/ml and $17.5(0-404) \mathrm{UI} / \mathrm{ml} 1$ year later (mean and range). Multivariate analyses revealed no association between peripheral sHLA-G expression and patients' asthmatic features, biological and clinical data, or HLA-G genetics (data not shown).

\section{HLA-G Haplotype Variation Defines Four Main Groups of Sequences}

Phylogenetic relationships for the 19 combinations of $H L A-G$ alleles and haplotypes with a frequency above $0.3 \%$ were investigated using the NJ method (Figure 1). The resulting phylogenetic tree shows a clustering that follows UTR variation. Indeed, four main clades can be defined: the first clade contains the H10UTR2 sequences ( $G^{\star} 01: 01: 02: 01, G^{\star} 01: 01: 02: 02, G^{\star} 01: 05 N$, and $\left.G^{\star} 01: 06\right)$, the second clade consists of the H23-UTR3 sequences $\left(G^{\star} 01: 04: 01\right.$ and $\left.G^{\star} 01: 04: 04\right)$, the third clade includes UTR5- $G^{\star} 01: 03: 01: 02$ sequences (haplotypes H21, H20, and H19), and the fourth clade assembles the UTR6, UTR4, and UTR1 sequences. This fourth clade had the most divergent sequences (associated with $G^{\star}$ 01:01:01:01 and $G^{\star}$ 01:01:01:05 alleles) as compared to a reference gorilla HLA-G sequence (Table 4). H16-UTR7-G*01:01:03:03 sequence formed an isolated branch situated above clade 1 .

\section{TF Binding Site Variations between HLA-G Haplotypes}

Thirty-four TFs were identified to bind differentially to each 5'URR sequence by in silico analysis (Tables 5 and $\mathbf{6}$ ), their classification is provided in Table 7; their specific expression in blood and lungs according to NCBI and TiGER databases is given in Table 6.

Interestingly, haplotype grouping based on their TF binding site profiles mirrored that observed on the phylogenetic tree (Table 6; Figure 1). Hence, haplotypes displayed different TF binding site profiles, notably in haplotype H23 (UTR3$G^{\star}$ 01:04:01/G*01:04:04): the transition $\mathrm{G}>\mathrm{A}$ at position -1155 impaired progesterone receptor $(\mathrm{PR})$ and SOX5 binding sites. Besides this unique feature, this haplotype displayed similarities with H16 (UTR7-G*01:01:03:03) and H10 (UTR2$\left.\mathrm{G}^{\star} 01: 06 / G^{\star} 01: 05 N / G^{\star} 01: 01: 02: X X\right)$. Comparing the most common sequences, some SNPs created new binding sites: one to two sites for SRF, one site for CUX1, two to three additional sites for POU2F1, one site for E2F, one site for glucocorticoid receptor, additional sites for SP1 (up to 10), one site for XFD-1, RXR, NR2C1, VDR, CDX1, and an additional site for HNF4. Conversely, some SNPs in H23, H16, and H10 disrupted binding sites for RUNX1, RFX1, and MYB. H16 and H10 differed from $\mathrm{H} 23$ and other haplotypes as their SNPs created a fixation site for Lmo complex, FOXI1, and GATA1 and disrupted a binding site for NF-E and TATA binding proteins.

Haplotypes H21, H19, and H20 (associated with UTR5$G^{\star}$ 01:03:01:02) distinguished themselves by an additional fixation site for ELK and IRF1, and the disruption of a fixation site for STAT; H19 and H20 displayed a disruption of a IKZF1 fixation site. H21 displayed an increase in REL binding sites. Genetic polymorphism in $\mathrm{H} 21, \mathrm{H} 19$, and $\mathrm{H} 20$ created a site for NF-1 and SREBF1 which were also present in haplotypes $\mathrm{H} 23, \mathrm{H} 16$, and $\mathrm{H} 10$. H21, H19, H20, H16, and $\mathrm{H} 10$ had a genetic polymorphism that created a site for TEF. Haplotypes H21, H19, H20, H23, H16, $\mathrm{H} 10, \mathrm{H} 04$, and $\mathrm{H} 02$ displayed a fixation site for C/EBP.

Concerning haplotypes associated with UTR6 $\left(G^{\star}\right.$ 01:01:01:01, $G^{\star}$ 01:01:01:04, $G^{\star}$ 01:01:01:06), H47 and H03 distinguished themselves by an additional site for REL and disruption of a fixation site for MEF-2. H46 and H49, H01, H05, and H54 and H04 and $\mathrm{H} 02$ displayed quite similar patterns, with the exception of $\mathrm{H} 54$ for which a fixation site for IKZF1 was disrupted, as for H19 and $\mathrm{H} 20$.

\section{Splicing Site Variation Analysis}

Variation in splicing sites was investigated for alleles with identical coding sequences but with variations at a six- or eight-digit level and sharing identical or similar haplotypes. 


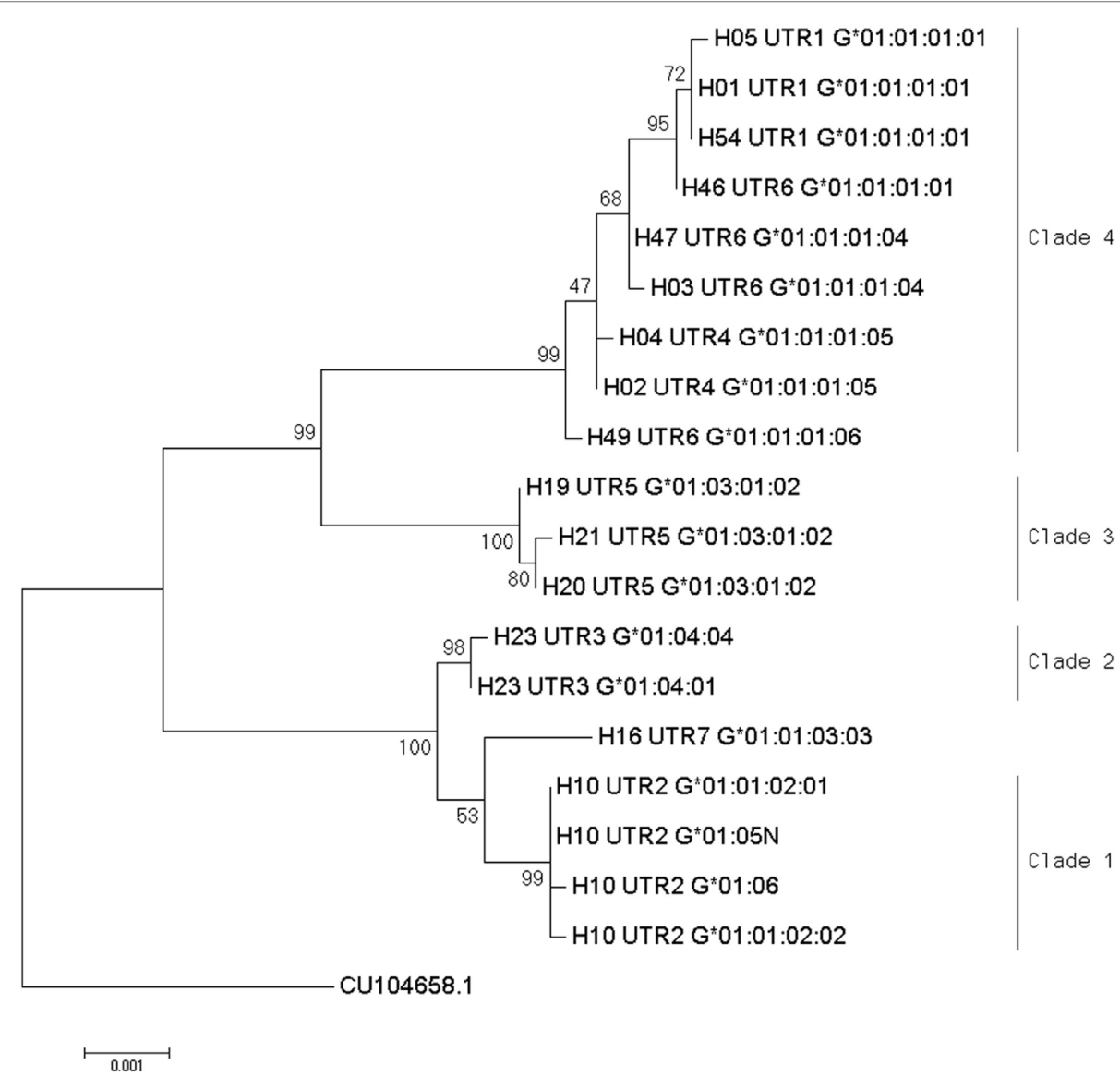

FIGURE 1 | Phylogenetic relationship between human leukocyte antigen-G (HLA-G) allele-haplotype sequences. The phylogenetic tree contains 19 sequences from -1983 to +3447 aligned using the multiple sequence alignment tool MUSCLE in the Molecular Evolutionary Genetics Analysis software version 7.0; sequences were H01-UTR1-G*01:01:01:01, H05-UTR1-G*01:01:01:01, H54-UTR1-G*01:01:01:01, H04-UTR4-G*01:01:01:05, H02-UTR4-G*01:01:01:05, H21UTR5-G*01:03:01:02, H20-UTR5-G*01:03:01:02, H19-UTR5-G*01:03:01:02, H10-UTR2-G*01:01:02:01, H10-UTR2-G*01:01:02:02, H10-UTR2-G*01:06, H10-UTR2-G*01:05N, H23-UTR3-G*01:04:01, H23-UTR3-G*01:04:04, H16-UTR7G*01:01:03:03, H46-UTR6-G*01:01:01:01, H47-UTR6-G*01:01:01:04, H03-UTR6-G*01:01:01:04, and H49-UTR6-G*01:01:01:06. Evolutionary relationships among HLA-G whole sequences were inferred using the neighbor-joining method with 1,000 replicates. Evolutionary distances were computed using the $p$-distance method, and units were the number of base differences per site. The percentage of trees in which the associated taxa clustered together is shown next to the branches. The sum of branch length equals 0.01616800 base differences per site. The percentage of replicate trees in which the associated taxa clustered together in the bootstrap test is shown next to the branches. The tree was drawn to scale, with branch lengths in the same units (base differences per site) as the evolutionary distances used to construct the phylogenetic tree. Analysis involved gorilla HLA-G genomic sequence as an outgroup (accession number CU104658.1).

$H L A-G^{\star} 01: 04: 01$ and $H L A-G^{\star}$ 01:04:04 alleles differ at position $1827 \mathrm{G}>\mathrm{A}$ in the last positions of exon $4 ; 1827 \mathrm{~A}$ in $H L A$ $G^{\star}$ 01:04:04 created an exonic cryptic acceptor site (Table 8A).

$H L A-G^{\star} 01: 01: 02: 01$ and $H L A-G^{\star} 01: 01: 02: 02$ alleles differ only at position $1016 \mathrm{C}>\mathrm{T}$ in intron 3 , this SNP did not have any impact on splicing site prediction.

HLA-G*01:01:01:01, HLA-G*01:01:01:04, HLA-G*01:01:01:05, and $H L A-G^{\star} 01: 01: 01: 06$ displayed eight variations in introns 2,3 and 4 (99G $>$ A, $126 \mathrm{~b} \mathrm{G}>\mathrm{A}, 130 \mathrm{~T}>\mathrm{C}, 482 \mathrm{~T}>\mathrm{C}, 494 \mathrm{~A}>\mathrm{C}, 505^{\star}>\mathrm{C}$, 531G $>\mathrm{C}, 1147 \mathrm{C}>\mathrm{T}) . H L A-G^{\star} 01: 01: 01: 01, H L A-G^{\star}$ 01:01:01:04, and $H L A-G^{\star} 01: 01: 01: 06$ had a disrupted intronic cryptic acceptor site as compared to $H L A-G^{*} 01: 01: 01: 05$ due to $99 \mathrm{G}>\mathrm{A}$ at the beginning of intron 2 and $494 \mathrm{~A}>\mathrm{C}$ at the beginning of intron 3 (Table 8B).

\section{DISCUSSION}

$H L A-G$ genetic polymorphism is extensively described in different human populations worldwide. However, there are only limited data describing the synergic effect of these SNPs, i.e., haplotypes, in clinical studies.

We fully characterized HLA-G haplotypes by NGS from position -1983 to +3447 both in a cohort of $330 \mathrm{HI}$ and in 580 patients from a French asthmatic multicenter cohort. sHLA-G was quantified using the ELISA test (MEM-G/9) in sera from 582 asthmatic patients and in 528 serum samples collected 1 year after the first sample. Associations between patients' asthmatic features, sHLA-G expression, and genetic polymorphism were tested with logistic regressions. 
TABLE 4 | Pairwise distance between each haplotype calculated by Molecular Evolutionary Genetics Analysis program.

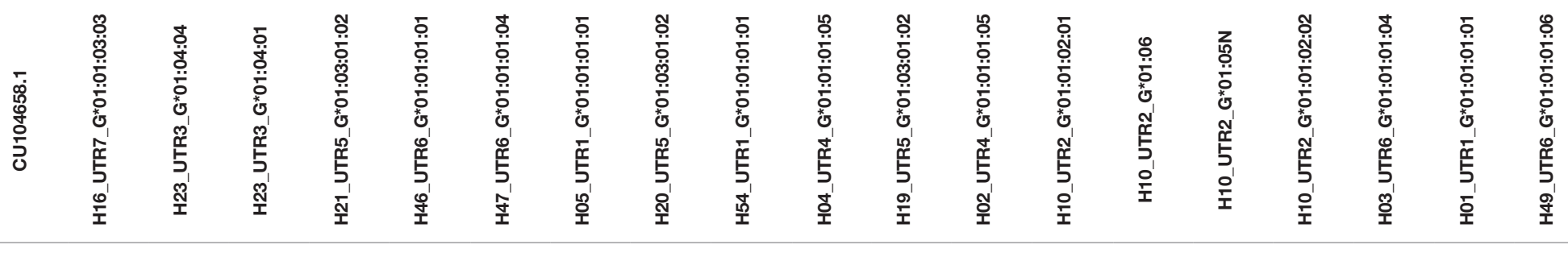

\section{CU104658.1}

H16_UTR7_G*01:01:03:03 H23_UTR3_G*01:04:04

H23_UTR3_G*01:04:01

H21_UTR5_G*01:03:01:02 H46_UTR6_G*01:01:01:01 H47_UTR6_G*01:01:01:04 H05_UTR1_G*01:01:01:01 H20_UTR5_G*01:03:01:02 H54_UTR1_G*01:01:01:01 H04_UTR4_G*01:01:01:05 H19_UTR5_G*01:03:01:02 H02_UTR4_G*01:01:01:05 H10_UTR2_G*01:01:02:01 H10_UTR2_G*01:06 H10_UTR2_G*01:05N H10_UTR2_G*01:01:02:02 H03_UTR6_G*01:01:01:04 H01_UTR1_G*01:01:01:01 H49_UTR6_G*01:01:01:06

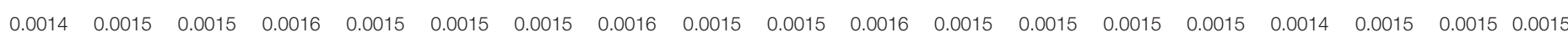

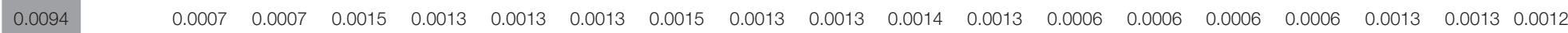
$\begin{array}{lllllllllllllllllll}0.0093 & 0.0024 & 0.0002 & 0.0014 & 0.0012 & 0.0012 & 0.0012 & 0.0014 & 0.0012 & 0.0012 & 0.0014 & 0.0012 & 0.0005 & 0.0006 & 0.0005 & 0.0005 & 0.0012 & 0.0012 & 0.0011\end{array}$ $\begin{array}{llllllllllllllllllll}0.0091 & 0.0022 & 0.0002 & 0.0014 & 0.0012 & 0.0012 & 0.0012 & 0.0014 & 0.0012 & 0.0012 & 0.0013 & 0.0012 & 0.0005 & 0.0005 & 0.0005 & 0.0005 & 0.0012 & 0.0012 & 0.0011 & 0.0014\end{array}$ $\begin{array}{lllllllllllllllllllll}0.0098 & 0.0087 & 0.0085 & 0.0084 & & 0.0013 & 0.0012 & 0.0013 & 0.0002 & 0.0013 & 0.0012 & 0.0002 & 0.0012 & 0.0013 & 0.0014 & 0.0014 & 0.0013 & 0.0012 & 0.0013 & 0.0012 & 0.0013\end{array}$ $\begin{array}{llllllllllllllllllllll}0.0104 & 0.0091 & 0.0085 & 0.0084 & 0.0063 & & 0.0003 & 0.0003 & 0.0012 & 0.0002 & 0.0005 & 0.0012 & 0.0004 & 0.0012 & 0.0013 & 0.0012 & 0.0012 & 0.0004 & 0.0002 & 0.0005 & 0.004\end{array}$ $\begin{array}{lllllllllllllllllll}0.0100 & 0.0089 & 0.0084 & 0.0082 & 0.0058 & 0.0006 & 0.0004 & 0.0012 & 0.0004 & 0.0004 & 0.0012 & 0.0003 & 0.0012 & 0.0013 & 0.0012 & 0.0012 & 0.0002 & 0.0004 & 0.0004\end{array}$

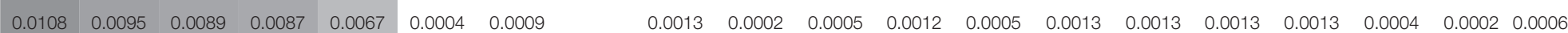
$\begin{array}{lllllllllllllllllllll}0.0098 & 0.0085 & 0.0084 & 0.0082 & 0.0002 & 0.0061 & 0.0056 & 0.0065 & & 0.0013 & 0.0012 & 0.0002 & 0.0012 & 0.0013 & 0.0014 & 0.0013 & 0.0013 & 0.0012 & 0.0013 & 0.0011\end{array}$ $\begin{array}{llllllllllllllllllllll}0.0108 & 0.0093 & 0.0087 & 0.0085 & 0.0065 & 0.0002 & 0.0007 & 0.0002 & 0.0063 & 0.0005 & 0.0012 & 0.0004 & 0.0012 & 0.0013 & 0.0012 & 0.0012 & 0.0004 & 0.0000 & 0.0006 & 0.006\end{array}$

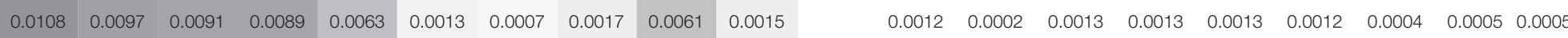
$\begin{array}{lllllllllllllllllll}0.0096 & 0.0083 & 0.0082 & 0.0080 & 0.0004 & 0.0059 & 0.0054 & 0.0063 & 0.0002 & 0.0061 & 0.0059 & 0.0011 & 0.0013 & 0.0014 & 0.0013 & 0.0013 & 0.0012 & 0.0012 & 0.0011\end{array}$ \begin{tabular}{llllllllllllllllllll}
0.0106 & 0.0095 & 0.0089 & 0.0087 & 0.0061 & 0.0011 & 0.0006 & 0.0015 & 0.0059 & 0.0013 & 0.0002 & 0.0058 & 0.0013 & 0.0013 & 0.0013 & 0.0013 & 0.0004 & 0.0004 & 0.0004 \\
\hline
\end{tabular} \begin{tabular}{l|lll|l|l|l|l|l|l|l|l|l|l|l|l|l|l|l}
0.0100 & 0.0020 & 0.0019 & 0.0017 & 0.0093 & 0.0093 & 0.0091 & 0.0097 & 0.0091 & 0.0095 & 0.0098 & 0.0089 & 0.0097 & 0.0002 & 0.0000 & 0.0002 & 0.0012 & 0.0012 & 0.0011
\end{tabular} \begin{tabular}{lllllll|l|l|l|l|l|l|l|l|l|l|l|l|l|l|l}
0.0102 & 0.0022 & 0.0020 & 0.0019 & 0.0094 & 0.0095 & 0.0093 & 0.0098 & 0.0093 & 0.0097 & 0.0100 & 0.0091 & 0.0098 & 0.0002 & 0.0002 & 0.0002 & 0.0013 & 0.0013 & 0.0012 \\
\hline
\end{tabular} \begin{tabular}{lllllll|l|l|l|l|l|l|l|l|l|l|l|l|l|l|l|l}
0.0100 & 0.0020 & 0.0019 & 0.0017 & 0.0093 & 0.0093 & 0.0091 & 0.0097 & 0.0091 & 0.0095 & 0.0098 & 0.0089 & 0.0097 & 0.0000 & 0.0002 & & 0.0002 & 0.0012 & 0.0012 & 0.0011
\end{tabular}

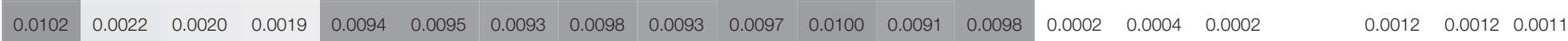
$\begin{array}{lllllllllllllllllllllll}0.0102 & 0.0091 & 0.0085 & 0.0084 & 0.0059 & 0.0007 & 0.0002 & 0.0011 & 0.0058 & 0.0009 & 0.0009 & 0.0056 & 0.0007 & 0.0093 & 0.0095 & 0.0093 & 0.0095 & 0.0004 & 0.0005\end{array}$ $\begin{array}{lllllllllllllllllll}0.0106 & 0.0093 & 0.0087 & 0.0085 & 0.0065 & 0.0002 & 0.0007 & 0.0002 & 0.0063 & 0.0000 & 0.0015 & 0.0061 & 0.0013 & 0.0095 & 0.0097 & 0.0095 & 0.0097 & 0.0009 & 0.0006\end{array}$ Color shades depict higher (red) and lower (green) values. Standard errors are shown in blue. 
TABLE 5 | 5'Upstream regulatory region polymorphism involved in the creation or the modification of factor transcription binding sites.

\begin{tabular}{|c|c|c|}
\hline Position & Allele 1 & Allele 2 \\
\hline$-1898 \mathrm{~T}>\mathrm{C}$ & None & TEF, SRF, IRF1 \\
\hline$-1746 \mathrm{C}>\mathrm{A}$ & TBP, NF-E & $\begin{array}{l}\text { FOX1, Lmo complex, } \\
\text { GATA1 }\end{array}$ \\
\hline$-1305 \mathrm{G}>\mathrm{A}$ & RUNX1 & C/EBP \\
\hline$-1179 A>G$ & None & SP1 \\
\hline$-1155 G>A$ & SOX5/PR & none \\
\hline$-1140 \mathrm{~A}>\mathrm{T}$ & None & POU2F1 \\
\hline$-1121 \mathrm{C}>\mathrm{T}$ & SP1 & None \\
\hline$-964 A>G$ & $\begin{array}{l}\text { NF-1, POU2F1, RXR, } \\
\text { VDR, SP1 }\end{array}$ & None \\
\hline$-725 \mathrm{C}>\mathrm{G}-716 \mathrm{G}>\mathrm{T}$ & None & C/EBP \\
\hline$-725 \mathrm{C}>\mathrm{T}-716 \mathrm{G}>\mathrm{T}$ & None & C/EBP, NF-1 \\
\hline$-689 G>A$ & E2F, MYB & 2 sites MYB \\
\hline$-666 \mathrm{~T}>\mathrm{G}$ & $\begin{array}{l}\text { XFD-1, NR2C1, SRF, } \\
\text { POU2F1 }\end{array}$ & None \\
\hline$-646 A>G$ & REL, PAX-4 & Augmentation REL \\
\hline$-633 A>G$ & CDX1 & RFX1 \\
\hline$-546{ }^{*}>G-540 A>*$ & $\begin{array}{l}\text { POU2F1, SP1, PAX-4, } \\
\text { IRF1, HNF1, MEF-2, C/ } \\
\text { EBP, IKZF1 }\end{array}$ & $\begin{array}{l}\text { POU2F1, SP1, PAX-4, } \\
\text { IRF1, HNF1, MEF-2, C/ } \\
\text { EBP }\end{array}$ \\
\hline$-486 \mathrm{C}>\mathrm{A}$ & NR3C1, SP1, HNF4 & None \\
\hline$-483 A>G$ & SP1, HNF4 & None \\
\hline$-477 \mathrm{G}>\mathrm{C}$ & SP1, SREBF1 & Diminution SREBF1 \\
\hline$-400 \mathrm{G}>\mathrm{A}$ & 2 sites SP1 & 1 site SP1 \\
\hline$-391 G>A$ & STAT, 1 site ELK & TEF, 2 sites ELK \\
\hline$-369 A>C$ & SP1 & 2 sites SP1 \\
\hline$-201 A>G$ & CUX1 & None \\
\hline$-56 \mathrm{C}>\mathrm{T}$ & SP1 & IRF1 \\
\hline
\end{tabular}

HLA-G haplotypes displayed statistically significant differential distribution between $\mathrm{HI}$ and asthmatic patients. Furthermore, multivariate analyses showed significant association of $H L A-G$ haplotypes with asthma inflammation markers (eosinophil count) and asthma severity (history of near-fatal asthma and exacerbation). We did not find any association between peripheral sHLA-G and genetic data in our asthmatic patient cohort; such an association described by us and others in physiological conditions may be masked in an inflammatory context as asthma. The lack of association between peripheral sHLA-G expression and asthmatic features supports the hypothesis that sHLA-G is not overexpressed as a systemic immune response to control local inflammation. These results reinforce the involvement of HLA-G in asthma and suggest that the modulation of local sHLA-G associated with asthma phenotypes and asthma inflammation markers described in Ref. (9) might be partly driven by $H L A-G$ genetic polymorphism.

We also performed descriptive analyses on full length $H L A-G$ sequences: phylogenetic analysis, in silico prediction of TF binding sites, and in silico prediction of splicing sites.

Phylogenetic analysis suggested a specific evolution of HLA$G$ haplotypes. HLA-G haplotype grouping based on their TF binding site profiles mirrored that observed on the phylogenetic tree.

UTR2-H10 was associated with asthmatic exacerbation within the previous 12 months and eosinophil count, and UTR7
(HLA-G $G^{\star}$ 1:01:03:03-H16) was associated with acute asthma recurrence. These sequences, the closest within the phylogenetic tree and according to TF binding site profiles, could lead to similar expression regulation. These results support the hypothesis of an impaired immunomodulation of the UTR2-HLA-G molecule, previously associated with a worse evolution of cystic fibrosis (23) and pregnancy complications $(37,38)$ for individuals carrying UTR2-HLA-G ${ }^{\star} 01: 06$.

Transcription factor binding site analysis supported a specific evolution of haplotype $\mathrm{H} 23$ that displayed an impaired PR site compared to other haplotypes. Progesterone is thought to play a major role in HLA-G expression because of concomitant requirement of both molecules for embryo implantation and pregnancy success. In vitro studies showed that progesterone enhanced HLA-G expression $(39,40)$. This unique feature of haplotype $\mathrm{H} 23$ may lead to an impaired activation of local HLA-G expression and a loss of local inflammation control. Haplotype $\mathrm{H} 23(\mathrm{Fq}=7.4 \%)$ was associated in the asthmatic patient cohort with higher eosinophil count in univariate analysis $(p=0.04)$; however, multiple correction testing did not reach statistical significance $(\mathrm{pc}=0.22)$. One may speculate, however, that a larger cohort may lead to statistical significance; thus this haplotype might be a good candidate marker for inflammation, as we previously associated UTR3-HLA-G*01:04 with impaired long-term survival following lung transplantation (23). Haplotype H23 is split into H23-UTR3-G*01:04:01 and H23-UTR3-G*01:04:04, respectively, higher and lower in $\mathrm{HI}$ than in asthmatic patients ( $p=0.044$ and $p=0.012$ ). These sequences differ at position $1827 \mathrm{G}>\mathrm{A}$ in the last positions of exon 4 which, according to in silico predictive analysis, creates an exonic cryptic acceptor site. We previously reported alternatively spliced isoform expression of HLA-G in HBEC from asthmatic patients as compared to HI forms (10). These results support the hypothesis that the mRNA transcript of these $H L A-G^{\star} 01: 04$ alleles might be processed differently leading to varied protein expression but could also explain discrepancies of clinical studies with $H L A-G$ typing at a four-digit level.

H04-UTR4- $G^{\star}$ 01:01:01:05 and H02-UTR4- ${ }^{\star} 01: 01: 01: 05$ were both higher in HI than in asthmatic patients $(p=0.015$ and $p=0.009$ ). No specific TF binding site was predicted by in silico analysis that could account for a putative protective effect; however, it could be due to a specific splicing process: when compared to its closest sequences (clade 4, Figure 1), HLA-G* 01:01:01:05 displayed, according to in silico predictive analysis, cryptic sites that are disrupted in $H L A-G{ }^{\star} 01: 01: 01: 01, H L A-G{ }^{\star} 01: 01: 01: 04$, and $H L A-G{ }^{\star} 01: 01: 01: 06$.

In conclusion, our results suggest that $H L A-G$ phylogeny reflects $H L A-G$ haplotype-specific association with different clinical conditions: clades 1, 2 and 3 gathered $H L A-G$ sequences associated with immune impairments in diverse pathological conditions (Figure 1) $(3,10,23)$. This study would benefit from the replication of pertinent results in additional cohorts to support the pertinence of defining HLA-G haplotype as a predictive genetic marker for asthma. Whereas the mechanisms with which HLA-G expression modulates asthma severity or phenotype are still poorly understood, it appears clearer that bronchial HLA-G 
TABLE 6 | Transcription factor (TF) binding site variation between human leukocyte antigen-G (HLA-G) haplotypes ("O" describes a loss of binding site; "1" a gain of binding site the sites variation; "-"a binding site diminution; and "+" a binding site augmentation).

\begin{tabular}{|c|c|c|c|c|c|c|c|c|c|c|c|c|c|c|c|c|c|}
\hline TF & $\begin{array}{l}\text { Expression } \\
\mathrm{NCBI}\end{array}$ & $\begin{array}{l}\text { Expression Tissue- } \\
\text { specific Gene } \\
\text { Expression and } \\
\text { Regulation (TiGER) }\end{array}$ & $\begin{array}{l}\text { H23 } \\
\text { UTR3 }\end{array}$ & $\begin{array}{l}\text { H10 } \\
\text { UTR2 }\end{array}$ & $\begin{array}{l}\text { H16 } \\
\text { UTR7 }\end{array}$ & $\begin{array}{l}\text { H21 } \\
\text { UTR5 }\end{array}$ & $\begin{array}{l}\text { H19 } \\
\text { UTR5 }\end{array}$ & $\begin{array}{l}\text { H20 } \\
\text { UTR5 }\end{array}$ & $\begin{array}{c}\text { H04 } \\
\text { UTR4 }\end{array}$ & $\begin{array}{c}\text { HO2 } \\
\text { UTR4 }\end{array}$ & $\begin{array}{l}\text { H49 } \\
\text { UTR6 }\end{array}$ & $\begin{array}{l}\text { H46 } \\
\text { UTR6 }\end{array}$ & $\begin{array}{l}\text { H05 } \\
\text { UTR1 }\end{array}$ & $\begin{array}{l}\text { H01 } \\
\text { UTR1 }\end{array}$ & $\begin{array}{l}\text { H54 } \\
\text { UTR1 }\end{array}$ & $\begin{array}{l}\text { H03 } \\
\text { UTR6 }\end{array}$ & $\begin{array}{c}\text { H47 } \\
\text { UTR6 }\end{array}$ \\
\hline SREBF1 & $w B c / L$ & $B / L$ & 1 & 1 & 1 & 1 & 1 & 1 & $1(-)$ & $1(-)$ & $1(-)$ & $1(-)$ & $1(-)$ & $1(-)$ & $1(-)$ & $1(-)$ & $1(-)$ \\
\hline RFX1 & $w B c / L$ & L & 0 & 0 & 0 & 1 & 1 & 1 & 1 & 1 & 1 & 1 & 1 & 1 & 1 & 1 & 1 \\
\hline NFE2 & $w B c / L$ & $\mathrm{~B}^{*} / \mathrm{L}$ & 1 & 0 & 0 & 1 & 1 & 1 & 1 & 1 & 1 & 1 & 1 & 1 & 1 & 1 & 1 \\
\hline C/EBP & $w B c / L$ & $B / L$ & 2 & 2 & 2 & 2 & 2 & 2 & 2 & 2 & 1 & 1 & 1 & 1 & 1 & 1 & 1 \\
\hline NF1 & $w B c / L$ & $B / L$ & 1 & 1 & 1 & 1 & 1 & 1 & 0 & 0 & 0 & 0 & 0 & 0 & 0 & 0 & 0 \\
\hline REL & $w B c / L$ & $B^{*} / L$ & 1 & 1 & 1 & $1(+)$ & 1 & 1 & 1 & 1 & 1 & 1 & 1 & 1 & 1 & 2 & 2 \\
\hline MEF-2 & $w B c / L$ & $L$ & 1 & 1 & 1 & 1 & 1 & 1 & 1 & 1 & 1 & 1 & 1 & 1 & 1 & 0 & 0 \\
\hline SRF & $w B c / L$ & $B / L$ & 1 & 2 & 2 & 0 & 0 & 0 & 0 & 0 & 0 & 0 & 0 & 0 & 0 & 0 & 0 \\
\hline RUNX1 & $w B c / L$ & $B^{*} / L$ & 0 & 0 & 0 & 1 & 1 & 1 & 1 & 1 & 1 & 1 & 1 & 1 & 1 & 1 & 1 \\
\hline sox5 & $\mathrm{L}$ & $B / L^{*}$ & 0 & 1 & 1 & 1 & 1 & 1 & 1 & 1 & 1 & 1 & 1 & 1 & 1 & 1 & 1 \\
\hline STAT & $w B c / L$ & $B / L$ & 1 & 1 & 1 & 0 & 0 & 0 & 1 & 1 & 1 & 1 & 1 & 1 & 1 & 1 & 1 \\
\hline TBP & $w B c / L$ & $B / L$ & 1 & 0 & 0 & 1 & 1 & 1 & 1 & 1 & 1 & 1 & 1 & 1 & 1 & 1 & 1 \\
\hline CDX1 & $x$ & $x$ & 1 & 1 & 1 & 0 & 0 & 0 & 0 & 0 & 0 & 0 & 0 & 0 & 0 & 0 & 0 \\
\hline CUX1 & $w B c / L$ & $B / L$ & 1 & 1 & 1 & 0 & 0 & 0 & 0 & 0 & 0 & 0 & 0 & 0 & 0 & 0 & 0 \\
\hline HNF1 & wBc & na & 1 & 1 & 1 & 1 & 1 & 1 & 1 & 1 & 1 & 1 & 1 & 1 & 1 & 0 & 0 \\
\hline $\begin{array}{l}\text { Lmo } \\
\text { complex }\end{array}$ & $x$ & $x$ & 0 & 1 & 1 & 0 & 0 & 0 & 0 & 0 & 0 & 0 & 0 & 0 & 0 & 0 & 0 \\
\hline $\mathrm{POU} 2 \mathrm{~F} 1$ & $w B c / L$ & $B / L$ & 3 & 4 & 4 & 1 & 1 & 1 & 1 & 1 & 1 & 1 & 1 & 1 & 1 & 1 & 1 \\
\hline IRF1 & $w B c / L$ & $B / L$ & 1 & 1 & 1 & 2 & 2 & 2 & 1 & 1 & 1 & 1 & 1 & 1 & 1 & 1 & 1 \\
\hline MYB & $w B c / L$ & $B / L$ & 1 & 1 & 1 & 2 & 2 & 2 & 2 & 2 & 2 & 2 & 2 & 2 & 2 & 2 & 2 \\
\hline ELK & $w B c / L$ & $B / L$ & 1 & 1 & 1 & 2 & 2 & 2 & 1 & 1 & 1 & 1 & 1 & 1 & 1 & 1 & 1 \\
\hline FOXI1 & $x$ & $B / L$ & 0 & 1 & 1 & 0 & 0 & 0 & 0 & 0 & 0 & 0 & 0 & 0 & 0 & 0 & 0 \\
\hline XFD-1 & $w B c / L$ & $B / L$ & 1 & 1 & 1 & 0 & 0 & 0 & 0 & 0 & 0 & 0 & 0 & 0 & 0 & 0 & 0 \\
\hline E2F & $w B c / L$ & L & 1 & 1 & 1 & 0 & 0 & 0 & 0 & 0 & 0 & 0 & 0 & 0 & 0 & 0 & 0 \\
\hline TEF & $w B c / L$ & L & 0 & 1 & 1 & 1 & 1 & 1 & 0 & 0 & 0 & 0 & 0 & 0 & 0 & 0 & 0 \\
\hline PAX-4 & $x$ & na & 2 & 2 & 2 & 1 & 2 & 2 & 2 & 2 & 2 & 2 & 2 & 2 & 2 & 1 & 1 \\
\hline GATA1 & $w B c / L$ & na & 0 & 1 & 1 & 0 & 0 & 0 & 0 & 0 & 0 & 0 & 0 & 0 & 0 & 0 & 0 \\
\hline IKZF1 & $w B c / L$ & $B^{\star} / L$ & 1 & 1 & 1 & 1 & 0 & 0 & 1 & 1 & 1 & 1 & 1 & 1 & 0 & 1 & 1 \\
\hline SP1 & $w B c / L$ & $B / L$ & 10 & 10 & 10 & 7 & 7 & 7 & 7 & 8 & 6 & 8 & 7 & 8 & 8 & 8 & 8 \\
\hline GR & $w B c / L$ & $B / L$ & 1 & 1 & 1 & 0 & 0 & 0 & 0 & 0 & 0 & 0 & 0 & 0 & 0 & 0 & 0 \\
\hline$P R$ & L & $B / L$ & 0 & 1 & 1 & 1 & 1 & 1 & 1 & 1 & 1 & 1 & 1 & 1 & 1 & 1 & 1 \\
\hline HNF4 & $x$ & $x$ & 2 & 2 & 2 & 1 & 1 & 1 & 1 & 1 & 1 & 1 & 0 & 1 & 1 & 1 & 1 \\
\hline RXR & $w B c / L$ & $\mathrm{~B}^{\star}$ & 1 & 1 & 1 & 0 & 0 & 0 & 0 & 0 & 0 & 0 & 0 & 0 & 0 & 0 & 0 \\
\hline $\mathrm{NR} 2 \mathrm{C} 1$ & $w B c / L$ & $x$ & 1 & 1 & 1 & 0 & 0 & 0 & 0 & 0 & 0 & 0 & 0 & 0 & 0 & 0 & 0 \\
\hline VDR & wBc/L & $B / L$ & 1 & 1 & 1 & 0 & 0 & 0 & 0 & 0 & 0 & 0 & 0 & 0 & 0 & 0 & 0 \\
\hline
\end{tabular}

TF expression in the lungs (L) or in blood (B) are shown according to NCBI and TiGER databases (L, expressed in the lungs; wBc, expressed in white blood cells; B, expressed in blood; $x$, no expression; na, not available; ${ }^{*} p$ value $<0.05)$. 
TABLE 7 | Transcription factors (TFs) identified to bind differentially to each 5'upstream regulatory region sequence, classification according to super class, class, and families.

\begin{tabular}{|c|c|c|c|}
\hline TF & Superclass & Class & Family \\
\hline SREBP & Basic domains & Helix-loop-helix/leucine Zipper factors (bHLHZIP) & Ubiquitous bHLH-ZIP factors \\
\hline$R F X 1$ & & Leucine zipper factors (bZIP) & AP-1(-like) components \\
\hline$N F-E$ & & Leucine zipper factors (bZIP) & AP-1(-like) components \\
\hline$C / E B P$ & & Leucine zipper factors (bZIP) & C/EBP-like factors \\
\hline$N F-1$ & & $\mathrm{NF}-1$ & $\mathrm{NF}-1$ \\
\hline$R E L$ & Beta-scaffold factors with minor groove & RHR (Rel homology region) & Rel/ankyrin \\
\hline MEF-2 & contacts & MADS box & Regulators of differentiation \\
\hline SRF (AGL3) & & MADS box & Responders to external signals \\
\hline RUNX1 (AML1) & & Runt & Runt \\
\hline SOX5 & & HMG & SOX \\
\hline STAT & & STAT & STAT \\
\hline TATA binding protein (TBP) & & TATA-binding proteins & TBP \\
\hline$C D \times 1$ & Helix-turn-helix & Homeodomain & Homeodomain only \\
\hline$C U \times 1$ (CDP-CR1) & & Homeodomain & Homeodomain only \\
\hline HNF1 & & Homeodomain & Homeodomain only \\
\hline Lmo complex & & Homeodomain & Homeodomain with LIM region \\
\hline POU2F1 (Oct1) & & Homeodomain & POU domain factors \\
\hline IRF1 & & Tryptophan clusters & Interferon-regulating factors \\
\hline$M Y B$ & & Tryptophan clusters & Myb \\
\hline ELK & & Tryptophan clusters & Ets-type \\
\hline FOXI1 (HFH-3) & & Fork head/winged helix & Other regulators \\
\hline$X F D-1$ & & Fork head/winged helix & Developmental regulators \\
\hline$E 2 F$ & & Fork head/winged helix & Cell-cycle controlling factors \\
\hline TEF & & TEA domain & TEA \\
\hline$P A X-4$ & & Paired box & \\
\hline GATA1 & Zinc-coordinating DNA-binding domains & diverse Cys4 zinc fingers & GATA-Factors \\
\hline IKZF1 (Ikaros-1) & & Cys2His2 zinc finger domain & Developmental/cell cycle regulators \\
\hline SP1 & & Cys2His2 zinc finger domain & Ubiquitous factors \\
\hline GR (NR3C1) & & Cys4 zinc finger of nuclear receptor type & Steroid hormone receptors \\
\hline$P R(N R 3 C 3)$ & & Cys4 zinc finger of nuclear receptor type & Steroid hormone receptors \\
\hline HNF4 & & Cys4 zinc finger of nuclear receptor type & Thyroid hormone receptor-like factors \\
\hline$R X R$ & & Cys4 zinc finger of nuclear receptor type & Thyroid hormone receptor-like factors \\
\hline TR2 (NR2C1) & & Cys4 zinc finger of nuclear receptor type & Thyroid hormone receptor-like factors \\
\hline VDR & & Cys4 zinc finger of nuclear receptor type & Thyroid hormone receptor-like factors \\
\hline
\end{tabular}

TABLE 8 | (A,B) Splicing site variation for $G^{*} 01: 01: 04: 01$ and $G^{\star} 01: 01: 04: 04$ (A) or $G^{\star} 01: 01: 01: 01, G^{*} 01: 01: 01: 04, G^{*} 01: 01: 01: 05$, and $G^{*} 01: 01: 01: 06$ (B).

\begin{tabular}{|c|c|c|}
\hline \multicolumn{3}{|l|}{ (A) } \\
\hline $\begin{array}{l}\text { Allele and exonic } \\
\text { cryptic sites }\end{array}$ & $\begin{array}{l}\text { 1827A, Acceptor } \\
\text { aggggctgccggAG }\end{array}$ & \\
\hline $\begin{array}{l}G^{\star} 01: 01: 04: 01 \\
1827 G\end{array}$ & Disrupted aggggctgccagAG & \\
\hline $\begin{array}{l}G^{\star} 01: 01: 04: 04 \\
1827 A\end{array}$ & Present & \\
\hline \multicolumn{3}{|l|}{ (B) } \\
\hline $\begin{array}{l}\text { Allele and intronic } \\
\text { cryptic sites }\end{array}$ & $\begin{array}{l}\text { 99A, Acceptor } \\
\text { ggagggaaacagCC }\end{array}$ & $\begin{array}{l}\text { 494A, Acceptor } \\
\text { cggcccagggagCA }\end{array}$ \\
\hline $\begin{array}{l}G^{\star} 01: 01: 01: 01 \\
99 G, 494 A\end{array}$ & Disrupted ggagggaaacggCC & Present \\
\hline $\begin{array}{l}G^{*} 01: 01: 01: 04 \\
99 G, 494 A\end{array}$ & Disrupted ggagggaaacggCC & Present \\
\hline $\begin{array}{l}G^{\star} 01: 01: 01: 05 \\
99 A, 494 A\end{array}$ & Present & Present \\
\hline $\begin{array}{l}G^{\star} 01: 01: 01: 06 \\
99 A, 494 C\end{array}$ & Present & $\begin{array}{l}\text { Disrupted } \\
\text { cggcccagggcgCA }\end{array}$ \\
\hline
\end{tabular}

expression is a more reliable marker than systemic and peripheral expression [(9) and our data]. However, given the discomfort of taking BAL samples and cross-reactivity in HLA-G antibody capture assays, $H L A-G$ haplotype sequencing offers a reproducible qualitative marker that can be obtained from a sampling method which is easy to implement. Our results support a phylogenetic evolution of $H L A-G$ sequences associated with differential qualitative and/or quantitative levels of protein expression, potentially driven by variations in TF binding sites and alternative splicing sites. Post-transcriptional mechanisms, not explored in this study, might also modify translation and shedding of sHLA-G and thus may further explain the lack of correlation observed between peripheral sHLA-G and genetic data in our asthmatic patient cohort.

This descriptive study does not address the putative role of HLA-G in impaired control of bronchial epithelium immune response and/or pro-inflammatory and pro-angiogenic responses described at the maternal fetal interface $(2,41,42)$, nor did we provide any experimental evidence for HLA-G haplotype actual involvement in HLA-G expression. 


\section{ETHICS STATEMENT}

This study was carried out in accordance with the French Public Health Code (art L1221-1). All subjects gave written informed consent in accordance with the Declaration of Helsinki. Asthmatic patients were enrolled in a French asthmatic multicenter cohort [Cohorte Obstruction Bronchique et Asthme (COBRA)].

\section{AUTHOR CONTRIBUTIONS}

CaR, FC, CeR, FJ, PG, GM, NM, JP, CP, JC, LA-R, PC, DG, JDC: substantial contributions to the conception or design of the work; or the acquisition, analysis, or interpretation of data for the work. CaR, FC, CeR, FJ, PG, GM, NM, JP, CP, JC, LA-R, PC, DG, JDC: drafting the work or revising it critically for important intellectual

\section{REFERENCES}

1. Morandi F, Rizzo R, Fainardi E, Rouas-Freiss N, Pistoia V. Recent advances in our understanding of HLA-G biology: lessons from a wide spectrum of human diseases. J Immunol Res (2016) 2016:4326495. doi:10.1155/2016/4326495

2. Ferreira LM, Meissner TB, Tilburgs T, Strominger JL. HLA-G: at the interface of maternal-fetal tolerance. Trends Immunol (2017) 38(4):272-86. doi:10.1016/j.it.2017.01.009

3. Rebmann V, da Silva Nardi F, Wagner B, Horn PA. HLA-G as a tolerogenic molecule in transplantation and pregnancy. J Immunol Res (2014) 2014:297073. doi:10.1155/2014/297073

4. Pabon MA, Navarro CE, Osorio JC, Gomez N, Moreno JP, Donado AF, et al. Impact of human leukocyte antigen molecules $\mathrm{e}, \mathrm{f}$, and $\mathrm{g}$ on the outcome of transplantation. Transplant Proc (2014) 46(9):2957-65. doi:10.1016/j. transproceed.2014.07.010

5. Ciprandi G, Corsico A, Pisati P. Serum-soluble HLA-G is associated with specific IgE in patients with allergic rhinitis and asthma. Inflammation (2014) 37(5):1630-4. doi:10.1007/s10753-014-9890-5

6. Zheng XQ, Li CC, Xu DP, Lin A, Bao WG, Yang GS, et al. Analysis of the plasma soluble human leukocyte antigen-G and interleukin-10 levels in childhood atopic asthma. Hum Immunol (2010) 71(10):982-7. doi:10.1016/j. humimm.2010.06.018

7. White SR, Loisel DA, McConville JF, Stern R, Tu Y, Marroquin BA, et al. Levels of soluble human leukocyte antigen-G are increased in asthmatic airways. Eur Respir J (2010) 35:925-7. doi:10.1183/09031936.00164809

8. Tahan F, Patiroglu T. Plasma soluble human leukocyte antigen G levels in asthmatic children. Int Arch Allergy Immunol (2006) 141(3):213-6. doi:10.1159/000095290

9. White SR, Nicodemus-Johnson J, Laxman B, Denner DR, Naureckas ET, Hogarth DK, et al. Elevated levels of soluble human leukocyte antigen-G in the airways are a marker for a low-inflammatory endotype of asthma. J Allergy Clin Immunol (2017) 140(3):857-60. doi:10.1016/j.jaci.2017.02.031

10. Carlini F, Picard C, Garulli C, Piquemal D, Roubertoux P, Chiaroni J, et al. Bronchial epithelial cells from asthmatic patients display less functional HLA-G isoform expression. Front Immunol (2017) 8:6. doi:10.3389/ fimmu.2017.00006

11. Zhang WQ, Xu DP, Liu D, Li YY, Ruan YY, Lin A, et al. HLA-G1 and HLAG5 isoforms have an additive effect on NK cytolysis. Hum Immunol (2014) 75(2):182-9. doi:10.1016/j.humimm.2013.11.001

12. Riteau B, Rouas-Freiss N, Menier C, Paul P, Dausset J, Carosella ED. HLA-G2, -G3, and -G4 isoforms expressed as nonmature cell surface glycoproteins inhibit NK and antigen-specific CTL cytolysis. J Immunol (2001) 166(8):5018-26. doi:10.4049/jimmunol.166.8.5018

13. Zhao L, Teklemariam T, Hantash BM. Mutated HLA-G3 localizes to the cell surface but does not inhibit cytotoxicity of natural killer cells. Cell Immunol (2014) 287(1):23-6. doi:10.1016/j.cellimm.2013.11.005

14. Eguchi H, Maeda A, Lo PC, Matsuura R, Esquivel EL, Asada M, et al. HLAG1, but not HLA-G3, suppresses human monocyte/macrophage-mediated content; final approval of the version to be published; agreement to be accountable for all aspects of the work in ensuring that questions related to the accuracy or integrity of any part of the work are appropriately investigated and resolved.

\section{ACKNOWLEDGMENTS}

The authors would like to thank the healthy donors and asthmatic patients who contributed toward this study.

\section{FUNDING}

This work was supported by Fondation du Souffle, Fonds de Dotation Recherche en Santé Respiratoire 2016.

swine endothelial cell lysis. Trans Proc (2016) 48(4):1285-7. doi:10.1016/j. transproceed.2015.10.070

15. Ferreira LM, Meissner TB, Mikkelsen TS, Mallard W, O’Donnell CW, Tilburgs T, et al. A distant trophoblast-specific enhancer controls HLA-G expression at the maternal-fetal interface. Proc Natl Acad Sci U S A (2016) 113(19):5364-9. doi:10.1073/pnas.1602886113

16. Svendsen SG, Hantash BM, Zhao L, Faber C, Bzorek M, Nissen MH, et al. The expression and functional activity of membrane-bound human leukocyte antigen-G1 are influenced by the 3'-untranslated region. Hum Immunol (2013) 74(7):818-27. doi:10.1016/j.humimm.2013.03.003

17. Tan Z, Randall G, Fan J, Camoretti-Mercado B, Brockman-Schneider R, Pan L, et al. Allele-specific targeting of microRNAs to HLA-G and risk of asthma. Am J Hum Genet (2007) 81(4):829-34. doi:10.1086/521200

18. Poras I, Yaghi L, Martelli-Palomino G, Mendes-Junior CT, Muniz YC, Cagnin NF, et al. Haplotypes of the HLA-G 3' untranslated region respond to endogenous factors of HLA-G+ and HLA-G- cell lines differentially. PLoS One (2017) 12(1):e0169032. doi:10.1371/journal.pone. 0169032

19. Porto IO, Mendes-Junior CT, Felicio LP, Georg RC, Moreau P, Donadi EA, et al. MicroRNAs targeting the immunomodulatory HLA-G gene: a new survey searching for microRNAs with potential to regulate HLA-G. Mol Immunol (2015) 65(2):230-41. doi:10.1016/j.molimm.2015.01.030

20. Moreau P, Flajollet S, Carosella ED. Non-classical transcriptional regulation of HLA-G: an update. J Cell Mol Med (2009) 13:2973-89. doi:10.1111/j.1582-4934.2009.00800.x

21. Nilsson LL, Djurisic S, Andersen AM, Melbye M, Bjerre D, Ferrero-Miliani L, et al. Distribution of HLA-G extended haplotypes and one HLA-E polymorphism in a large-scale study of mother-child dyads with and without severe preeclampsia and eclampsia. HLA (2016) 88(4):172-86. doi:10.1111/ $\tan .12871$

22. Castelli EC, Mendes-Junior CT, Veiga-Castelli LC, Roger M, Moreau P, Donadi EA. A comprehensive study of polymorphic sites along the HLA-G gene: implication for gene regulation and evolution. Mol Biol Evol (2011) 28(11):3069-86. doi:10.1093/molbev/msr138

23. Di Cristofaro J, Reynaud-Gaubert M, Carlini F, Roubertoux P, Loundou A Basire A, et al. HLA-G*01:04 UTR3 recipient correlates with lower survival and higher frequency of chronic rejection after lung transplantation. Am J Transplant (2015) 15(9):2413-20. doi:10.1111/ajt.13305

24. Nicolae D, Cox NJ, Lester LA, Schneider D, Tan Z, Billstrand C, et al. Fine mapping and positional candidate studies identify HLA-G as an asthma susceptibility gene on chromosome 6p21. Am J Hum Genet (2005) 76(2):349-57. doi:10.1086/427763

25. Ober C. HLA-G: an asthma gene on chromosome 6p. Immunol Allergy Clin North Am (2005) 25(4):669-79. doi:10.1016/j.iac.2005.08.001

26. Nicodemus-Johnson J, Laxman B, Stern RK, Sudi J, Tierney CN, Norwick L, et al. Maternal asthma and microRNA regulation of soluble HLA-G in the airway. J Allergy Clin Immunol (2013) 131(6):1496-503. doi:10.1016/j.jaci. 2013.01.037 
27. Naidoo D, Wu AC, Brilliant MH, Denny J, Ingram C, Kitchner TE, et al. A polymorphism in HLA-G modifies statin benefit in asthma. Pharmacogenomics $J$ (2015) 15(3):272-7. doi:10.1038/tpj.2014.55

28. Carlini F, Traore K, Cherouat N, Roubertoux P, Buhler S, Cortey M, et al. HLA-G UTR haplotype conservation in the Malian population: association with soluble HLA-G. PLoS One (2013) 8(12):e82517. doi:10.1371/journal. pone. 0082517

29. Di Cristofaro J, El Moujally D, Agnel A, Mazieres S, Cortey M, Basire A, et al. HLA-G haplotype structure shows good conservation between different populations and good correlation with high, normal and low soluble HLA-G expression. Hum Immunol (2013) 74(2):203-6. doi:10.1016/j.humimm.2012. 10.027

30. Robinson J, Halliwell JA, Hayhurst JD, Flicek P, Parham P, Marsh SG. The IPD and IMGT/HLA database: allele variant databases. Nucleic Acids Res (2015) 43:D423-31. doi:10.1093/nar/gku1161

31. Nunes JM. Using uniformat and gene[rate] to analyse data with ambiguities in population genetics. Evol Bioinform Online (2016) 11(Suppl 2):19-26. doi:10.4137/EBO.S32415

32. Kumar S, Stecher G, Tamura K. MEGA7: molecular evolutionary genetics analysis version 7.0 for bigger datasets. Mol Biol Evol (2016) 33(7):1870-4. doi:10.1093/molbev/msw054

33. Liu X, Yu X, Zack DJ, Zhu H, Qian J. TiGER: a database for tissue-specific gene expression and regulation. BMC Bioinformatics (2008) 9:271. doi:10.1186/ 1471-2105-9-271

34. Desmet FO, Hamroun D, Lalande M, Collod-Beroud G, Claustres M, Beroud C. Human Splicing Finder: an online bioinformatics tool to predict splicing signals. Nucleic Acids Res (2009) 37(9):e67. doi:10.1093/nar/gkp215

35. Castelli EC, Ramalho J, Porto IO, Lima TH, Felicio LP, Sabbagh A, et al. Insights into HLA-G genetics provided by worldwide haplotype diversity. Front Immunol (2014) 5:476. doi:10.3389/fimmu.2014.00476

36. Castelli EC, Gerasimou P, Paz MA, Ramalho J, Porto IO, Lima TH, et al. HLA-G variability and haplotypes detected by massively parallel sequencing procedures in the geographicaly distinct population samples of Brazil and Cyprus. Mol Immunol (2017) 83:115-26. doi:10.1016/j.molimm.2017. 01.020
37. Moreau P, Contu L, Alba F, Lai S, Simoes R, Orru S, et al. HLA-G gene polymorphism in human placentas: possible association of $\mathrm{G}^{*} 0106$ allele. Biol Reprod (2008) 79(3):459-67. doi:10.1095/biolreprod.108.068874

38. Tan CY, Ho JF, Chong YS, Loganath A, Chan YH, Ravichandran J, et al. Paternal contribution of HLA-G*0106 significantly increases risk for pre-eclampsia in multigravid pregnancies. Mol Hum Reprod (2008) 14(5):317-24. doi:10.1093/ molehr/gan013

39. Sheshgiri R, Rao V, Tumiati LC, Xiao R, Prodger JL, Badiwala M, et al. Progesterone induces human leukocyte antigen-g expression in vascular endothelial and smooth muscle cells. Circulation (2008) 118(14 Suppl):S58-64. doi:10.1161/CIRCULATIONAHA.107.757781

40. Sheshgiri R, Rouas-Freiss N, Rao V, Butany J, Ramzy D, Krawice-Radanne I, et al. Myocardial HLA-G reliably indicates a low risk of acute cellular rejection in heart transplant recipients. J Heart Lung Transplant (2008) 27(5):522-7. doi:10.1016/j.healun.2008.02.004

41. Li C, Houser BL, Nicotra ML, Strominger JL. HLA-G homodimer-induced cytokine secretion through HLA-G receptors on human decidual macrophages and natural killer cells. Proc Natl Acad Sci U S A (2009) 106(14):5767-72. doi:10.1073/pnas.0901173106

42. Le Bouteiller P. HLA-G in human early pregnancy: control of uterine immune cell activation and likely vascular remodeling. Biomed $J$ (2015) 38(1):32-8. doi:10.4103/2319-4170.131376

Conflict of Interest Statement: The authors declare that the research was conducted in the absence of any commercial or financial relationships that could be construed as a potential conflict of interest.

Copyright (C) 2018 Ribeyre, Carlini, René, Jordier, Picard, Chiaroni, Abi-Rached, Gouret, Marin, Molinari, Chanez, Paganini, Gras and Di Cristofaro. This is an open-access article distributed under the terms of the Creative Commons Attribution License (CC BY). The use, distribution or reproduction in other forums is permitted, provided the original author(s) and the copyright owner are credited and that the original publication in this journal is cited, in accordance with accepted academic practice. No use, distribution or reproduction is permitted which does not comply with these terms. 